\title{
Development and validation of spectrophotometric method for determination of gabapentin in bulk and pharmaceutical dosage forms based on Schiff base formation with salicylaldehyde
}

\author{
Ihab M. Almasri*, Mai Ramadan, Eman Algharably \\ Department of Pharmaceutical Chemistry \& Pharmacognosy, Faculty of Pharmacy, Al Azhar University-Gaza, Gaza, Palestine.
}

\begin{tabular}{|c|c|}
\hline ARTICLE INFO & ABSTRACT \\
\hline $\begin{array}{l}\text { Received on: } 22 / 07 / 2018 \\
\text { Accepted on: } 20 / 01 / 2019 \\
\text { Available online: } 30 / 03 / 2019\end{array}$ & $\begin{array}{l}\text { A sensitive, simple, and economic spectrophotometric method was developed and validated for the determination of } \\
\text { gabapentin in pure form and pharmaceutical preparations. The method is based on Schiff base condensation reaction of } \\
\text { the primary amino group of gabapentin with salicylaldehyde reagent in the presence of acetate solution at } 45^{\circ} \mathrm{C} \text { for } 20 \\
\text { minutes. The obtained yellow-colored derivative in methanolic medium showed absorption maxima at } 403 \mathrm{~nm} \text {. Under }\end{array}$ \\
\hline $\begin{array}{l}\text { Key words: } \\
\text { UV-Vis, spectrophotometric, } \\
\text { derivatization, gabapentin, } \\
\text { salicylaldehyde. }\end{array}$ & $\begin{array}{l}\text { the optimum conditions, Beer's law was obeyed in the concentration range of } 6 \text { to } 100 \mu \mathrm{g} / \mathrm{ml} \text { with correlation coefficient } \\
\text { value of } 0.9961 \text {. Limit of detection and limit of quantification were found to be } 1.16 \text { and } 3.48 \mu \mathrm{g} / \mathrm{ml} \text {, respectively. The } \\
\text { validity of the described method was assessed according to the International Conference on Harmonization guidelines. } \\
\text { The mean percentage recoveries } \pm \mathrm{SD} \text { were } 100.57 \pm 1.5 \text { by applying the standard addition technique. The method was } \\
\text { repeatable and precise (RSD } \leq 0.61 \% \text { and } \leq 1.34 \% \text {, respectively) and was successfully applied for the determination } \\
\text { of the investigated drug in its pharmaceutical dosage form without detectable interference from the additives, hence, } \\
\text { can be suggested for routine analysis of the gabapentin. }\end{array}$ \\
\hline
\end{tabular}

\section{INTRODUCTION}

Gabapentin (GBP), chemically known as 1-(aminomethyl) cyclohexaneacetic acid (Fig. 1), has a molecular formula of $\mathrm{C}_{9} \mathrm{H}_{17} \mathrm{NO}_{2}$ and a molecular weight of 171.24 (USP 32, 2009). GBP is a white to almost white crystalline powder that is sparingly soluble in water, slightly soluble in ethanol $(96 \%)$, and practically insoluble in methylene chloride. It dissolves in dilute acids and dilute solutions of alkali hydroxides. A $2 \%$ solution of GBP in water has a pH of 6.5 to 7.5 (BP, 2015; Martindale 36, 2009).

Although GBP was originally developed as anticonvulsant in the treatment of epilepsy as a structural analogue of gamma-aminobutyric acid, the precise mechanism by which GBP produces its analgesic and antiepileptic actions is yet unknown. However, it is believed to involve voltage-gated N-type calcium

\section{"Corresponding Author}

Ihab M. Almasri, Department of Pharmaceutical Chemistry \&

Pharmacognosy, Faculty of Pharmacy, Al Azhar University-Gaza, Gaza.

E-mail: ihabalmasri@yahoo.com ion channels in the central nervous system, reducing calcium influx into the nerve terminals. In this way, the nerves become less excitable, reducing the release of other neurotransmitters (Davies et al., 2007; Fornasari, 2017).

GBP is used for the treatment of complex partial seizures, with or without secondary generalization. It is currently used as a medication to relieve pain, especially neuropathic pain and as an

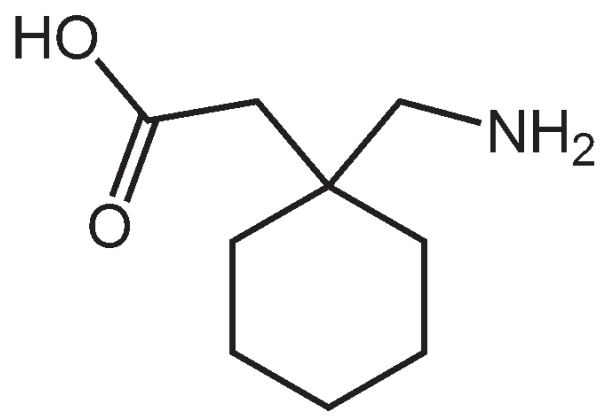

Figure 1. Chemical structure of gabapentin. 


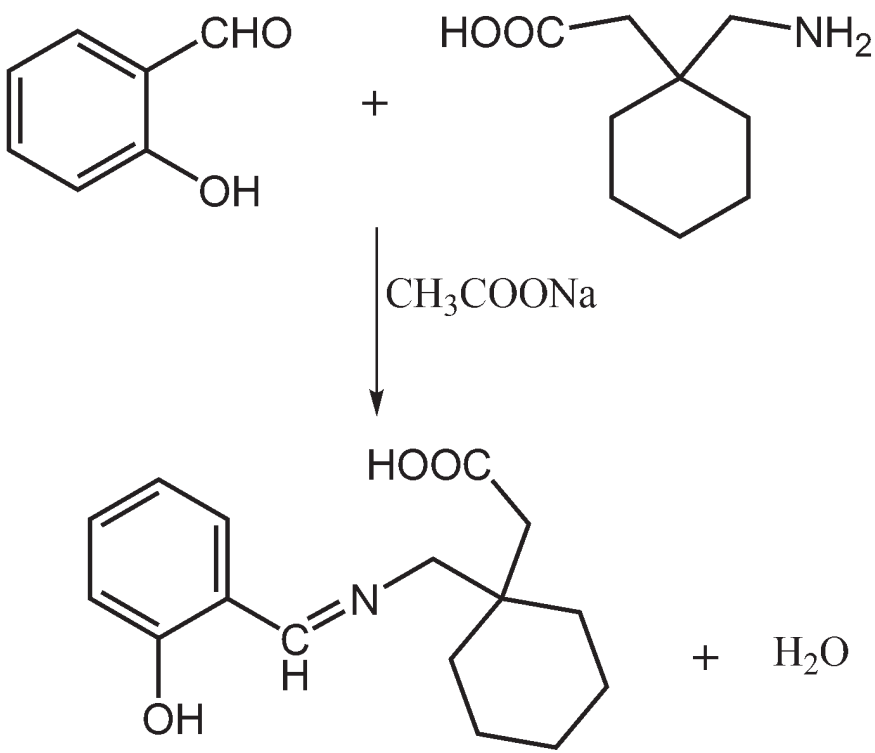

Figure 2. Schematic representation of proposed reaction of gabapentin with SA.

adjunct for the treatment of acute postsurgical pain (Behnam et al., 2012; McNamara, 2011).

Reviewing the literature revealed that several direct and indirect analytical methods which based on gas chromatography (GC), high performance liquid chromatography (HPLC), capillary electrophoresis (CE), UV-Vis spectrophotometry, and spectrofluorometry have been used for the determination of GBP in pure form, pharmaceutical formulations, and/or biological samples either alone or in combination with other drugs.

Various methods that have been reported for the determination of GBP mostly rely on chromatographic techniques, especially HPLC with various detection methods (Gupta et al., 2008; Ojha et al., 2007; Rao et al., 2009; Yagi et al., 2012). They are more labor-intensive, time-consuming, not easy to work with them, and their columns and solvents are either expensive, hazardous, or not available. In addition, GC (Borrey et al., 2005) and CE methods (Cao et al., 2012) reported for the GBP determination require long and tedious pretreatment of the samples and laborious clean up procedures prior to analysis. They are likely to be limited by routine availability of these techniques.

Several spectroscopic methods were developed for GBP analysis in pure form and in pharmaceutical formulations either with spectrophotometric or spectrofluorimetric determination. Due to the absence of strong absorbing chromophore in GBP, its direct spectrophotometric analysis is problematic and mostly depends on the derivatization with chemical reagents (Adegbolagun et al., 2018; Adegoke et al., 2018; Ambala and Patel, 2011; Fonseca et al., 2017; Gouda and Malah, 2013; Gujral et al., 2009; Saleh et al., 2014; Siddiqui et al., 2010). The official methods for the identification and quantitation analysis of GBP are prescribed in BP and USP (BP, 2015; USP $32,2009)$

UV-Vis spectrophotometry is widely used for the quality control of pharmaceuticals because of its distinctive advantages such as lower cost, robustness, simplicity, good accuracy, and precision. Therefore, a new, simple, sensitive, and accurate derivatization spectrophotometric method for the determination of GBP in pure form as well as in pharmaceutical formulations was developed in which, the use of salicylaldehyde (SA) as a derivatizing reagent for gabapentin was examined, for the first time, to produce a chromophore detectable by UV-Vis detector. The proposed method based on the formation of Schiff's bases (imine compound) as a result of condensation reaction of primary amino group of GBP with active carbonyl group of SA in the presence of acetate solution in one-step reaction (Fig. 2), which did not require vigorous conditions, extraction, or any clean-up step prior to detection in comparing with other reported procedures (Ambala and Patel, 2011).

\section{MATERIALS AND METHODS}

\section{Instruments}

Double beam scanning UV-Vis Spectrophotometer (Shimadzu 1601, Japan) with $1 \mathrm{~cm}$ matched quartz cell connected to a computer with UV-Probe software. Thermostatically controlled water bath (SB-24, Tokyo Aikakikai, Japan) and $\mathrm{pH}$ meter (Shimadzu, Japan) were used.

\section{Reagents and chemicals}

GBP standard was kindly donated by Bet Jalla Company (Ramallah, Palestine). Commercially available pharmaceutical dosage form, gabapentin capsules (300 $\mathrm{mg} / \mathrm{capsule}$ ), was purchased from the local market. Analytical grade Methanol was purchased from Merk (Germany). SA, glacial acetic acid, and sodium acetate supplied by (Sigma-Aldrich, Germany). Pharmaceutical grade excipients: starch, lactose monohydrate, magnesium stearate, and talc were kindly supplied by domestic pharmaceutical companies.

\section{Preparation of reagents}

\section{SA solution $0.3 \%(v / v)$}

SA reagent was prepared by accurately transferring $0.30 \mathrm{ml}$ of SA into $100-\mathrm{ml}$ volumetric flask, mixed thoroughly with warm methanol, and completed the volume to $100 \mathrm{ml}$ with methanol. The solution was freshly prepared daily and protected from light.

\section{Sodium acetate solution $0.6 \%(w / v)$}

The solution was prepared by dissolving $0.60 \mathrm{gm}$ of sodium acetate in $100 \mathrm{ml}$ volumetric flask using distilled water.

\section{Acetate buffer solutions}

Acetate buffer solutions were prepared by weighing and transferring different amounts of sodium acetate into 1,000 $\mathrm{ml}$ volumetric flask, dissolved with distilled water, then different volumes of acetic acid solution $2 \mathrm{M}$ were added and then the volume completed with distilled water to $1,000 \mathrm{ml}$ (USP 32, 2009).

\section{Gabapentin standard solution}

Standard GBP stock solution $(2 \mathrm{mg} / \mathrm{ml})$ was freshly prepared by dissolving $100 \mathrm{mg}$ of GBP standard in $50-\mathrm{ml}$ volumetric flask using distilled water. 


\section{Selection of analytical wavelength for chromogen}

Into two $10 \mathrm{ml}$ volumetric flasks, 0.1 and $0.4 \mathrm{ml}$ of GBP stock solution $(2 \mathrm{mg} / \mathrm{ml})$ were transferred and then $2 \mathrm{ml}$ of SA $0.3 \%(\mathrm{v} / \mathrm{v})$ solution followed by $1 \mathrm{ml}$ of sodium acetate $0.6 \%(\mathrm{w} / \mathrm{v})$ solution were added. The content of each flask was shaken thoroughly and heated on a water bath at $45^{\circ} \mathrm{C}$ for 20 minutes. The flasks were left to cool for 10 minutes, then volume was completed with methanol to have 20 and $80 \mu \mathrm{g} / \mathrm{ml}$ GBP, respectively. The absorption spectra and absorption maxima of the resulting solutions (chromogen) were determined against a blank prepared in the same manner without the examined drug.

\section{Optimization of reaction conditions}

\section{Effect of temperature}

The effect of temperature on the reaction was studied by carrying out the reaction at different temperatures: RT, $35^{\circ} \mathrm{C}$, $40^{\circ} \mathrm{C}, 45^{\circ} \mathrm{C}, 50^{\circ} \mathrm{C}, 55^{\circ} \mathrm{C}, 60^{\circ} \mathrm{C}$, and $70^{\circ} \mathrm{C}$.

\section{Effect of solvent}

The effect of solvent on the absorbance of chromogen was studied using distilled water and methanol for the dilution of final samples.

\section{Effect of volume of SA $0.3 \%(\mathrm{v} / \mathrm{v})$ solution}

The effect of concentration of SA solution was studied by measuring the absorbance of GBP derivative with different added reagent volumes: $1.0,1.5,2.0$, and $2.5 \mathrm{ml}$ of SA $0.3 \%(\mathrm{v} / \mathrm{v})$ solution.

\section{Effect of volume of sodium acetate $0.6 \%(w / v)$ solution}

The effect of concentration of sodium acetate solution was studied by measuring the absorbance of GBP derivative with different added volumes: $0.5,1.0,1.5$, and $2.0 \mathrm{ml}$ of sodium acetate solution $0.6 \%(\mathrm{w} / \mathrm{v})$.

\section{Effect of $p H$}

The effect of $\mathrm{pH}$ was studied by measuring the absorbance of GBP derivative at different $\mathrm{pH}$ of acetate buffer solutions: $4,4.5,5,5.5$, and 7.5 .

\section{Effect of reaction time}

The effect of reaction time was studied by carrying out the reaction for different time periods: $5,10,15,20,25$, and 30 minutes.

\section{Effect of order of addition}

The effect of reagents addition order was studied by carrying out the reaction in different orders.

\section{General procedure for gabapentin determination}

Into $10 \mathrm{ml}$ volumetric flask, $0.4 \mathrm{ml}$ of GBP stock solution ( $2 \mathrm{mg} / \mathrm{ml}$ ) was transferred followed by $2 \mathrm{ml}$ of SA reagent and 1 $\mathrm{ml}$ of sodium acetate solution. The content of the flask was shaken thoroughly and heated on a water bath at $45^{\circ} \mathrm{C}$ for 20 minutes. The flask left to cool for 10 minutes and the volume was completed with the methanol. The absorbance of the resulting solution was measured at $403 \mathrm{~nm}$ against a blank prepared in the same manner without the examined drug.

\section{Construction of calibration curve for gabapentin}

Accurately measured aliquots of GBP stock solution were transferred into separate $10-\mathrm{ml}$ volumetric flasks and then the general procedure for gabapentin determination [Section "General procedure for gabapentin determination"] was conducted to produce standard solutions having concentrations of $6-100 \mu \mathrm{g} / \mathrm{ml}$. The absorbances of these standard solutions were measured at 403 $\mathrm{nm}$ and calibration curve was plotted. The correlation coefficient $(r)$, slope and intercept, and molar absorptivity of the drug were determined using the calibration curve.

\section{Method validation}

Analytical method validation was performed according to the ICH guidelines (2005) with respect to accuracy, precision, specificity, linearity, limit of detection (LOD), and limit of quantitation (LOQ).

\section{Linearity and range}

The linearity of the proposed method was determined by measuring the absorbance of six concentrations $(6,10,20$, 40,80 , and $100 \mu \mathrm{g} / \mathrm{ml}$ of GBP) covering the range $(6-100 \mu \mathrm{g} /$ $\mathrm{ml})$. Five measurements were done for each concentration. The absorbance was plotted against concentration. The regression line and correlation coefficient were evaluated as well as validity of regression line was verified by statistical analysis.

\section{Specificity}

The specificity of the method was investigated by adding the common used excipients in the preparation of GBP formulations (starch, magnesium stearate, talc, and lactose) to the drug, then procedure was followed as described and the percent of the drug recovery was calculated.

\section{Accuracy}

Accuracy of the method was ascertained by performing recovery studies using standard addition method, in which standard drug aliquots were added at three different levels (20, 40 , and $60 \mu \mathrm{g} / \mathrm{ml}$ ) to a pre-analyzed sample of GBP capsule powder equivalent to $20 \mu \mathrm{g} / \mathrm{ml}$. These three concentrations were measured and each of them was repeated three times to calculate the accuracy.

\section{Precision}

Intraday precision was assessed by analysis of three different concentrations $(20,80$, and $100 \mu \mathrm{g} / \mathrm{ml})$ of the drug at three different time periods of the same day. The relative standard deviation (RSD) was calculated for each concentration. On the other hand, inter-day precision was studied by repeating the procedure for three different concentrations $(20,80$, and $100 \mu \mathrm{g} /$ $\mathrm{ml}$ ) of the drug on three different days and RSD was calculated for each concentration.

\section{$L O D$ and $L O Q$}

The LOD is expressed using the following formula (ICH, 2005); $\mathrm{LOD}=3.3 \sigma / \mathrm{S}$ and the $\mathrm{LOQ}$ is expressed using the 


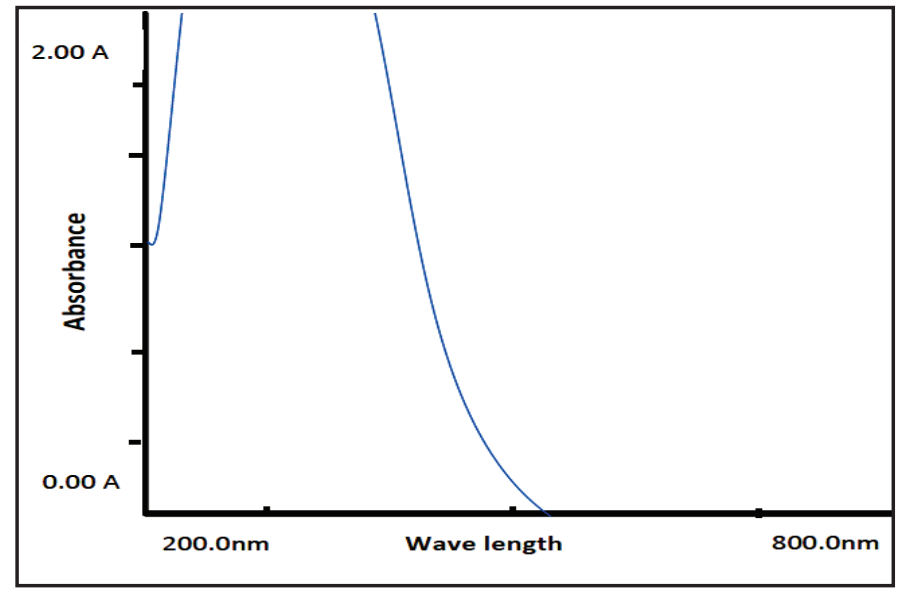

Figure 3. Absorption spectrum of blank solution of SA and sodium acetate against methanol.

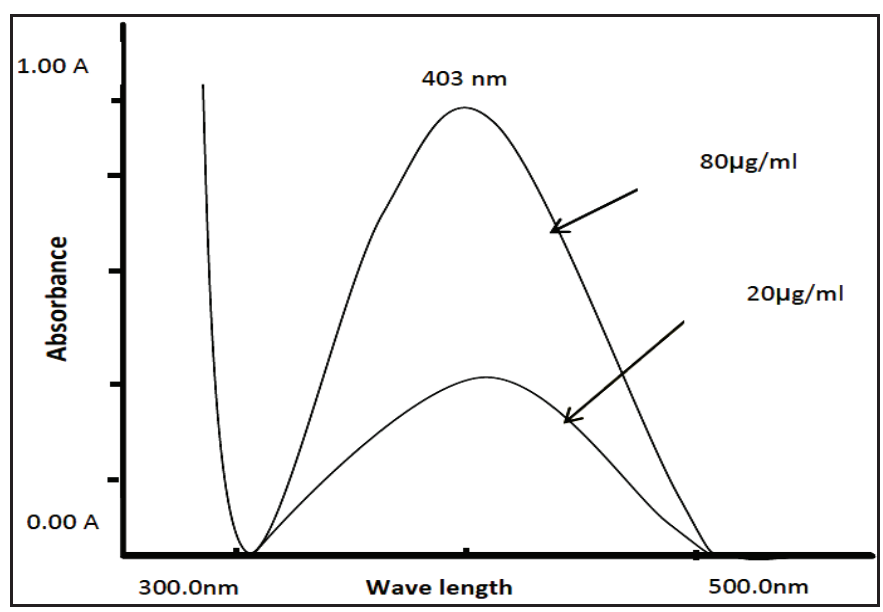

Figure 4. Absorption spectrums of GBP derivative product (20 and $80 \mu \mathrm{g} / \mathrm{ml})$

following formula (ICH, 2005); $\mathrm{LOQ}=10 \sigma / S$; where, $\sigma$ is the standard deviation of residuals of the regression line and $S$ is the slope of the regression line.

\section{Stability of chromogen}

The effect of time on the stability of chromogen was studied by following the absorption of the resulting GBP derivative at different time intervals up to 1 hour at $403 \mathrm{~nm}$ after the completion of the flask's volume with methanol against the blank.

\section{Application to gabapentin pharmaceutical dosage form (capsules)}

Twenty capsules were emptied, weighed, and mixed thoroughly. An accurately weighed portion of the resulting powder equivalent to $100 \mathrm{mg} \mathrm{GBP}$ was taken, dissolved in $25 \mathrm{ml}$ distilled water with good shaking for 5-10 minutes, then filtered with filter paper to remove insoluble matter. The filtrate solution was diluted to $50 \mathrm{ml}$ with distilled water to prepare $2-\mathrm{mg} / \mathrm{ml}$
Table 1. Summary of optimum conditions for reaction of GBP with SA.

\begin{tabular}{lcc}
\hline Variable & Studied range & Result \\
\hline Solvent & Methanol or water & Methanol \\
Volume of $0.3 \%(\mathrm{v} / \mathrm{v})$ SA solution $(\mathrm{mL})$ & $1.0-2.5$ & 2.0 \\
Volume of $0.6 \%$ sodium acetate solution $(\mathrm{mL})$ & $0.5-2.0$ & 1.0 \\
$\mathrm{pH}$ & $4-7.5$ & 7.5 \\
Temperature $\left({ }^{\circ} \mathrm{C}\right)$ & $25-70$ & 45 \\
Reaction time $(\mathrm{min})$ & $5-30$ & 20 \\
Order of addition & Different & No effect
\end{tabular}

solution. 0.2 and $0.4 \mathrm{ml}$ of the resulting solution were transferred into two $10 \mathrm{ml}$ volumetric flasks then the procedure was followed as described above (Section "General procedure for gabapentin determination"). Triplicate measurements were done for each concentration and the percentage of recovery was calculated from the calibration curve.

\section{RESULTS AND DISCUSSION}

The reaction of aldehydes or ketones with ammonia or $1^{\circ}$-amines forms imine derivatives, also known as Schiff base). Water is eliminated in the reaction, which is acid-catalyzed and reversible in the same sense as acetal formation. The $\mathrm{pH}$ for imine-producing reactions must be carefully controlled. The rate, at which these compounds are formed, is generally greatest near a $\mathrm{pH}$ of 5, and drops at higher and lower $\mathrm{pH}$ 's (Sorrell, 2006).

\section{Selection of analytical wavelength for chromogen}

The derivatization reaction between GBP and SA was performed and the absorption spectrum of the formed yellowcolored product in methanolic medium was scanned against the blank. The blank was also scanned against methanol in the range of 200-800 nm (Fig. 3). It was found that the absorbance of the derivative product increased directly with GBP concentration and exhibiting $\lambda_{\max }$ at $403 \mathrm{~nm}$ (Fig. 4) at which selectivity enhanced through avoiding interferences from excipients in contrast to shorter $\lambda_{\max }$ of other reviewed methods (Siddiqui et al., 2010).

\section{Optimization of derivatization reaction conditions}

To optimize the reaction variables, the effects of temperature, solvent, reaction time, $\mathrm{pH}$, and concentrations of SA and sodium acetate on the absorbance of the formed product, with respect to maximum sensitivity and adherence to Beer's law, were studied through controlled experiments. The results of the optimization studies are summarized in Table 1.

\section{Method validation}

\section{Linearity}

The calibration curve was constructed by plotting the absorbance of the drug versus the drug concentration within the specified range. A linear correlation was found between concentration and absorbance in the range 6-100 $\mu \mathrm{g} / \mathrm{ml}$ (Fig. 5) 


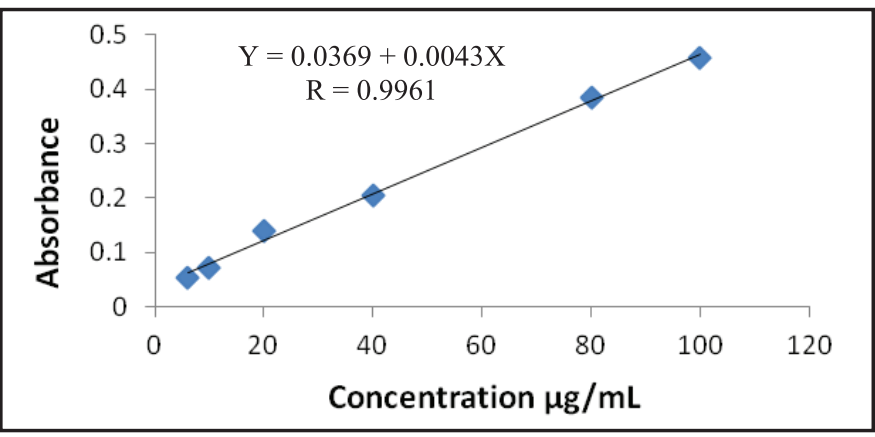

Figure 5. Calibration curve of GBP analysis (mean of five replicates).

Table 2. Results of specificity study for GBP analysis.

\begin{tabular}{ccc}
\hline Concentration $(\boldsymbol{\mu g} / \mathbf{m l})$ & $\begin{array}{c}\text { Amount recovered } \\
(\boldsymbol{\mu g} / \mathbf{m L})\end{array}$ & \% Recovery $^{\mathbf{a}} \pm \mathbf{S D}$ \\
\hline \multirow{2}{*}{90} & 90.76 & \\
& 89.12 & $99.88 \pm 0.91$ \\
& 89.80 & \\
60 & 60.79 & $100.26 \pm 1.07$ \\
& 59.51 & \\
\hline
\end{tabular}

${ }^{a}$ Values are mean of three determinations.

with a correlation coefficient equal to 0.9961 . Molar absorptivity of GBP chromogen was calculated $(\varepsilon=684.951 / \mathrm{mol} . \mathrm{cm})$. The LOD and LOQ for the proposed method were found to be 1.16 and $3.48 \mu \mathrm{g} / \mathrm{ml}$, respectively. These obtained parameters were comparable to the parameters obtained in published spectrophotometric methods of analysis of GBP (Ambala and Patel, 2011).

\section{Specificity}

The specificity of the method was investigated by observing any interference encountered from common excipients, usually used in the pharmaceutical formulations of GBP. The degree of interference was evaluated by measuring the percentage recovery of GBP at two concentration levels (60 and $90 \mu \mathrm{g} / \mathrm{ml}$ ) with various amounts of diverse excipients added to the drug. No interference was found in the analysis of GBP as shown in Table 2.

\section{Accuracy}

Accuracy of the method was ascertained by performing recovery studies using a standard addition method. The obtained results in Table 3 showed excellent mean recovery percent values $(102.22 \%-99.28 \%)$ with low SD values $(\leq 1.5)$ which indicate high accuracy of the proposed analytical method.

\section{Precision}

Intraday precision was assessed and the results are summarized in Table 4. RSD values were found to be very small $(<1.0 \%)$ indicating high repeatability of the proposed method. Moreover, the inter-day precision was also assessed and the results are summarized in Table 4. The obtained RSD values
Table 3. Results of recovery study for gabapentin analysis.

\begin{tabular}{|c|c|c|c|}
\hline $\begin{array}{c}\text { Base level } \\
(\mu \mathrm{g} / \mathrm{mL})\end{array}$ & $\begin{array}{l}\text { Spiked amount } \\
(\mu \mathrm{g} / \mathrm{mL})\end{array}$ & $\begin{array}{c}\text { Recovered amount } \\
(\mu \mathrm{g} / \mathrm{mL})\end{array}$ & $\%$ Recovery $^{\mathrm{a}} \pm$ SD \\
\hline & & 40.05 & \\
\hline \multirow[t]{3}{*}{20} & $\mathrm{t} 20$ & 40.02 & $100.21 \pm 0.085$ \\
\hline & & 40.05 & \\
\hline & & 59.89 & \\
\hline \multirow[t]{3}{*}{20} & 40 & 59.51 & $99.28 \pm 0.477$ \\
\hline & & 59.73 & \\
\hline & & 81.41 & \\
\hline \multirow[t]{2}{*}{20} & 60 & 81.88 & $102.22 \pm 0.99$ \\
\hline & & 80.71 & \\
\hline
\end{tabular}

${ }^{a}$ Values are mean of three determinations.

Table 4. Evaluation of the precision of the analytical procedure of gabapentin.

\begin{tabular}{|c|c|c|c|c|c|}
\hline & $\begin{array}{c}\text { Actual amount } \\
(\mu \mathrm{g} / \mathrm{ml})\end{array}$ & $\begin{array}{c}\text { Recovered amount } \\
(\mu \mathrm{g} / \mathrm{ml})\end{array}$ & Mean $^{\mathrm{a}}$ & SD & RSD \\
\hline \multirow[t]{9}{*}{ Intraday } & & 20.15 & & & \\
\hline & 20 & 19.90 & 20.03 & 0.13 & 0.62 \\
\hline & & 20.03 & & & \\
\hline & & 80.02 & & & \\
\hline & 80 & 80.72 & 80.64 & 0.59 & 0.73 \\
\hline & & 81.19 & & & \\
\hline & & 100.1 & & & \\
\hline & 100 & 99.63 & 100.1 & 0.47 & 0.47 \\
\hline & & 100.57 & & & \\
\hline \multirow[t]{9}{*}{ Inter-day } & & 20.01 & & & \\
\hline & 20 & 19.78 & 19.86 & 0.13 & 0.67 \\
\hline & & 19.78 & & & \\
\hline & & 81.41 & & & \\
\hline & 80 & 79.30 & 80.47 & 1.07 & 1.34 \\
\hline & & 80.71 & & & \\
\hline & & 99.79 & & & \\
\hline & 100 & 98.86 & 99.33 & 0.47 & 0.47 \\
\hline & & 99.33 & & & \\
\hline
\end{tabular}

aalues are mean of three determinations.

were less than $1.34 \%$ indicating good precision of the proposed method.

\section{Stability of chromogen}

It was found that the use of methanol as a solvent yielded good results in terms of the stability of GBP derivative which remained at least for 1 hour after dilution and this is sufficient time for the performance of the analysis for many samples.

\section{Application to gabapentin pharmaceutical dosage form}

The developed spectrophotometric method has been successfully applied to the determination of GBP in capsules. The percentage of recovery mean for GBP capsules was 101.01 \pm 1.23 which is satisfactory and very close to the label claim and lie within the USP accepted range $(90 \%-110 \%$; USP 32,2009$)$. 
Table 5. Determination of gabapentin in capsules by developed method and comparison with validated published method.

\begin{tabular}{lcc}
\hline \multirow{2}{*}{ Dosage form } & \multicolumn{2}{c}{$\%$ Recovery $^{\mathrm{a}} \pm$ SD } \\
\cline { 2 - 3 } & Proposed method $^{\text {Published method }}$ \\
\hline GBP capsules $300 \mathrm{mg}$ & $101.01 \pm 1.231$ & $99.91 \pm 0.567^{\mathrm{b}}$ \\
& $\mathrm{t}=0.014^{\mathrm{c}}$ & \\
\hline
\end{tabular}

${ }^{a}$ Values are mean of six determinations.

${ }^{b}$ Results for GBP determination in capsule by published method (Gujral et al., 2009). ${ }^{\text {cTabulated }} \mathrm{t}_{0.05,10}$ value $=2.23$ at $95 \%$ confidence level and 10 degrees of freedom.

The percentage of recovery with low values of standard deviation indicates the accuracy and precision of the proposed method (Table 5). The estimated drug content obtained by the proposed method was statistically comparable to the results obtained by a published method (Gujral et al., 2009). No significance difference was found at $95 \%$ confidence level $(p$ value $<0.05)$ as shown in Table 5 .

\section{CONCLUSION}

The present study described the development and validation of a simple spectrophotometric assay for the determination of GBP. The obtained results revealed that the proposed method is time saving, precise, accurate and do not require prior extraction procedure or heating and have the advantages of simplicity and sensitivity. Hence, it could be concluded that the developed method could be successfully applied in routine analysis for GBP determination in bulk and in pharmaceutical dosage forms.

\section{REFERENCES}

Adegbolagun OM, Thomas OE, Aiyenale EO, Adegoke OA. A new spectrophotometric method for the determination of gabapentin using chromotropic acid. Acta Pharm Sci, 2018; 56(3):93-110.

Adegoke OA, Adegbolagun OM, Aiyenale EO, Thomas OE. New spectrophotometric method for the determination of gabapentin in bulk and dosage forms using p-dimethylaminobenzaldehyde. J Taibah Univ Sci, 2018; 12(6):754-64.

Ambala PS, Patel NJ. Visible spectrophotometric methods for determination of gabapentin in pharmaceutical tablet and capsule dosage forms. Asian J Pharmacy Life Sci, 2011; 1(3):223-33.

Behnam B, Semnani V, Saghafi N, Ghorbani R, Shori MD, Choobmasjedi SG. Gabapentin effect on pain associated with heroin withdrawal in Iranian crack: a randomized double-blind clinical trial. Iran J Pharm Res, 2012; 11:979-83.

Borrey DCR, Godderis KO, Engelrelst VIL, Bernard DR, Langlois MR. Quantitative determination of vigabatrin and gabapentin in human serum by gas chromatography-mass spectrometry. J Clin Chim Acta, 2005; 354(1-2):147-51.

British Pharmacopoeia. Monograph of gabapentin. The Department of Health, The Stationary Office London, UK, 2015.

Cao L, Liang S, Tan X, Meng J. Determination of gabapentin in human plasma by capillary electrophoresis-laser induced fluorescence detection with and without solid-phase extraction. J Microchim Acta, 2012; 178(3-4):285-92.

Davies A, Hendrich J, Van Minh AT, Wratten J, Douglas L, Dolphin AC. Functional biology of the $\alpha 26$ subunits of voltage-gated calcium channels. Trends Pharmacol Sci, 2007; 28:220-8.

Fonseca F, Brito de Barros R, Ilharco LM, Garcia AR. Spectroscopic methods for quantifying gabapentin: framing the methods without derivatization and application to different pharmaceutical formulations. Appl Spectrosc, 2017; 71(11):2519-31.

Fornasari D. Pharmacotherapy for neuropathic pain: a review. Pain Ther, 2017; 6(Suppl 1):25-33.

Gouda AA, Malah ZA. Development and validation of sensitive spectrophotometric method for determination of two antiepileptics in pharmaceutical formulations. Spectrochim Acta A Mol Biomol Spectrosc, 2013; 105:488-96.

Gujral RS, Haque SM, Shanker P. A sensitive UV spectrophotometric method for the determination of gabapentin. E-J Chem, 2009; 6(S1):163-70.

Gupta A, Ciavarella AB, Sayeed VA, Khan MA, Faustino PJ. Development and application of a validated HPLC method for the analysis of dissolution samples of gabapentin drug products. J Pharm Biomed Anal, 2008; 46(1):181-6.

International Conference on Harmonization (ICH). Validation of analytical procedures: text and methodology Q2(R1). International Conference on Harmonization (ICH), Q2(R1), Geneva, Switzerland, pp 1-13.

Sweetman SC. Martindale: the complete drug reference. In Antiepileptics. 36th edition, Pharmaceutical Press, London, UK, pp 482-3, 2009.

McNamara JO. Pharmacotherapy of the epilepsies. In Brunton LL, Chabner BA, Knollman BC (eds.). Goodman \& Gilman's the pharmacological basis of therapeutics. 12th edition, The McGraw-Hill Companies, New York, NY, pp 583-608, 2011.

Ojha A, Rathod R, Patel C, Padh H. LC-MS determination of gabapentin from human plasma. Chromatographia, 2007; 66:853-7.

Rao BU, Maqdoom F, Nikalje AP. Determination of gabapentin in bulk drug and in pharmaceutical dosage form by HPLC method. J Chil Chem Soc, 2009; 54(4):424-7.

Saleh MS, Youssef AK, Hashem EY, Abdel-Kader DA. A novel spectrophotometric method for determination of gabapentin in pharmaceutical formulations using 2,5-dihydroxybenzaldehyde. Comput Chem, 2014; 2:22-30.

Siddiqui FA, Arayne MS, Sultana N, Rehman N. Spectrophotometric determination of gabapentin in pharmaceutical formulations using ninhydrin and $\pi$-acceptors. Eur J Med Chem, 2010 45(7):2761-7.

Sorrell TN. Addition-elimination reactions of aldehydes and ketones. In Organic chemistry. 2nd edition, University Science Books, California, pp 669-700, 2006

United States Pharmacopeia, USP. NF 27. Monograph of gabapentin. 32nd edition, Asian Edition, United States Pharmacopeial Convention, Inc., Rockville, MD, 2009.

Yagi T, Naito T, Mino Y, Takashina Y, Umemura K, Kawakami J. Rapid and validated fluorometric HPLC method for determination of gabapentin in human plasma and urine for clinical application. J Clin Pharm Ther, 2012; 37(1):89-94.

How to cite this article:

Almasri IM, Ramadan M, Algharably E. Development and validation of spectrophotometric method for determination of gabapentin in bulk and pharmaceutical dosage forms based on Schiff base formation with salicylaldehyde. J Appl Pharm Sci, 2019; 9(03):021-026. 